\title{
RESPONSABILIDADE ENUNCIATIVA EM TEXTOS ACADÊMICO-CIENTÍFICOS: POR UM TRATAMENTO TEXTUAL/DISCURSIVO DAS OPERAÇÕES DE CITAÇÃO
}

ENUNCIATIVE RESPONSABILITY IN ACADEMIC AND SCIENTIFIC TEXTS: FOR A TEXTUAL/DISCURSIVE TREATMENT OF CITATION PROCEDURES

\author{
Rosângela Alves dos Santos Bernardino* \\ Universidade do Estado do Rio Grande do Norte, Pau dos Ferros, RN, Brasil
}

\begin{abstract}
Resumo: Com base em categorias e marcas linguísticas da responsabilidade enunciativa, tal como propõe o quadro teórico da Análise Textual dos Discursos (ADAM, 2011), e em articulação com estudos do campo enunciativo (RABATEL, 2009; AUTHIER-REVUZ, 1990, 1998; GUENTCHÉVA, 1994), entre outros, este trabalho propõe uma reflexão acerca do tratamento dedicado às operações de citação em manuais de metodologia científica. Como alternativa ao aspecto essencialmente técnico e prescritivo evidenciado nos manuais examinados, colocamos em debate alguns direcionamentos didático-metodológicos que permitem compreender a citação e explorar seus variados mecanismos por um viés textual/discursivo e que, assim, possam nortear a produção e o ensino de textos na universidade, em particular na graduação.
\end{abstract}

Palavras-chave: Responsabilidade enunciativa; Autoria; Texto acadêmico; Operações de citação.

Abstract: Based on categories and linguistic marks of enunciative responsibility, as purposed by the theoretical framework of Textual Analysis of Discourses (ADAM, 2011), and in conjunction with studies of enunciative field (RABATEL, 2009; AUTHIER-REVUZ, 1990, 1998; GUENTCHÉVA, 1994), among others, this paper proposes a reflection about treatment dedicated to citation procedures in manuals of scientific methodology. As an alternative to the essentially technical and prescriptive aspect evidenced in manuals examined, we put up for debate some didactic-pedagogical directions that allows us to understand citation and to explore its diverse mechanisms by a textual/ discursive perspective and thus can guide the production and teaching of texts in the university, especially at graduation.

Keywords: Enunciative Responsibility. Authorship. Academic Text. Citation Procedures.

* Professora doutora na Universidade do Estado do Rio Grande do Norte, Pau dos Ferros, Brasil; rosealves_23@yahoo.com.br 
Linha D'Água (Online), São Paulo, v. 31, n. 1, p. 193-220, jan.-abril 2018

\section{Considerações iniciais}

No contexto universitário ${ }^{1}$, nem sempre as situações de ensino de textos acadêmico-científicos conseguem abarcar os aspectos linguísticos, textuais e discursivos inerentes à produção de sentidos dos variados gêneros de discurso. Em geral, o foco recai sobre os aspectos organizacionais, estruturais e técnicos, em sintonia com os manuais de metodologia científica e/ou por eles influenciados. Assim, um elemento tão relevante e complexo, como é o caso da citação, não costuma receber o tratamento devido, de forma que abarque as sutilezas relativas ao uso de marcadores linguísticos, ao posicionamento do locutor-enunciador no discurso, ao gerenciamento das vozes, à construção de voz própria.

Em sintonia com os resultados obtidos em pesquisa doutoral, na qual articulamos as noções de responsabilidade enunciativa e autoria, sob o enfoque da Análise Textual dos Discursos (doravante ATD) e de teorias enunciativas, para investigar as estratégias de materialização da responsabilidade enunciativa e de inscrição de voz autoral mobilizadas em artigos científicos de pesquisadores iniciantes, visamos aqui promover uma discussão decorrente das contribuições que a noção teórica de responsabilidade enunciativa pode conferir ao ensino das operações de citação, com o propósito específico de apresentarmos direcionamentos para como abordá-la a partir de um viés que complemente e avance em relação à orientação técnica dos manuais de metodologia do trabalho científico.

As reflexões aqui feitas e as sugestões de tratamento didático-metodológico são direcionadas ao ensino de textos acadêmico-científicos na graduação e colocam em cena a citação como um recurso que permite assinalar a responsabilidade enunciativa e evidenciar os posicionamentos do primeiro locutor-enunciador em relação aos discursos reportados. Isso porque, ao citar o discurso de outrem, o autor mobiliza diversos elementos linguísticos que dizem respeito ao fenômeno da responsabilidade enunciativa (ADAM, 2011), sobretudo nos contextos de imputação, isto é, de atribuição de um ponto de vista a outrem (RABATEL, 2009; 2016).

\footnotetext{
1 Versão condensada e modificada do capítulo da tese de doutorado (BERNARDINO, 2015), desenvolvida no Programa de Pós-graduação em Estudos da Linguagem (PPgEL/UFRN), com o apoio da CAPES, sob a mediação do Programa Observatório da Educação (OBEDUC) e orientação da Profa. Dra. Maria das Graças Soares Rodrigues.
} 
Linha D'Água (Online), São Paulo, v. 31, n. 1, p. 193-220, jan.-abril 2018

Ao delimitar esse foco, a discussão proposta aqui pretende também se somar à contribuição de outros autores a respeito do ensino da produção textual na universidade. No contexto da pesquisa no Brasil, a obra de Motta-Roth e Hendges (2010), por exemplo, traz informações sistematizadas para orientar a produção de gêneros acadêmico-científicos, como o resumo, a resenha e o artigo científico, tendo como aporte teórico a abordagem da Sociorretórica, visando ao desenvolvimento do letramento científico de pesquisadores iniciantes.

Outro exemplo é a obra organizada por Silva (2012a), que apresenta um conjunto de trabalhos dedicados a discutir alternativas de didatização de gêneros produzidos na esfera acadêmica, especialmente o esquema, o resumo, o artigo científico e a resenha, sob o enfoque da Linguística Aplicada e da perspectiva de ensino de Língua Portuguesa para fins específicos. Entretanto, estas e as outras publicações existentes ainda não é suficiente para dar conta das muitas questões que recobrem a temática da produção textual no universo acadêmico-científico, especificamente em se tratando das dificuldades ligadas à citação.

Por razões de espaço, as noções teóricas mobilizadas neste trabalho serão retomadas ao longo do texto. Uma noção central que nos ampara é a de responsabilidade enunciativa como categoria inseparável ou correlata ao ponto de vista (doravante PdV) e que, conforme Adam $(2011,110)$, "permite dar conta do desdobramento polifônico" dos enunciados. Inscrita na dimensão enunciativa do texto - sendo este concebido como "unidade de sentido em contexto" - a responsabilidade enunciativa pode ser assinalada a partir de diferentes graus, suscitando, de um lado, o total engajamento do locutor-enunciador ou, de outro, o seu distanciamento pelo conteúdo proposicional relatado. Materialmente, pode ser sinalizada por meio de elementos linguísticos como: indices de pessoas, dêiticos espaciais e temporais, tempos verbais, modalidades, diferentes tipos de representação da fala, indicações de quadros mediadores, fenômenos de modalização autonímica, indicações de um suporte de percepçóes e de pensamentos.

Conforme Adam (2011), tais elementos constituem-se como categorias da responsabilidade enunciativa, cada uma exibindo uma diversidade de marcas linguísticas específicas e que permite abrir o horizonte para filiações teóricas também distintas. Aqui, focalizamos especificamente três delas: os diferentes tipos 
Linha D'Água (Online), São Paulo, v. 31, n. 1, p. 193-220, jan.-abril 2018

de representação da fala, as indicações de quadros mediadores e os fenômenos de modalização autonímica, cujos referenciais teóricos serão mobilizados no momento em que as mencionarmos em nossos apontamentos analíticos sobre os dados.

Ainda em termos conceituais, a responsabilidade enunciativa "consiste na assunção por determinadas entidades ou instâncias do conteúdo do que é enunciado, ou na atribuição de alguns enunciados ou PdV a certas instâncias." (PASSEGGI et al., 2010, p. 299). Dizendo com as palavras de Rabatel (2016, p. 88), podemos distinguir, de uma parte, a responsabilidade enunciativa "para os conteúdos proposicionais que o locutor/enunciador primeiro (L1/E1) assume por conta própria, porque ele os julga verdadeiros, e, de outra, a imputação para os conteúdos proposicionais que L1/E1 atribui a um enunciador segundo (e2)."

Assim concebida, a responsabilidade enunciativa pode ser, também, totalmente ligada à construção da autoria, uma vez que o PdV suscita uma instância que se responsabiliza pelo seu conteúdo proposicional, ainda mais se nossa unidade de análise trata-se de textos concretos. O texto de Rabatel (2010), ao retomar o conceito de função-autor ou autoria, advindo da obra de Foucault (1969 [2012]), nos faz pensar que ser autor vai muito além de assumir os PdV alheios, uma vez que requer a contribuição pessoal, a formulação de uma voz própria, mesmo diante de um conjunto de trabalhos anteriores.

Assumimos, pois, que a autoria é um conceito bastante útil à análise da construção interacional dos $\mathrm{PdV}$ do L1/E1, porque permite verificar como estes se relacionam com os $\mathrm{PdV}$ de outrem. Relativamente ao contexto da pesquisa científica e da produção textual que dela resulta, é possível observar se a autoria no texto acadêmico-científico limita-se à assunção da responsabilidade enunciativa pelas vozes alheias ou, quando não cai por completo nessa redução, em que medida sinaliza um avanço, uma originalidade, que, por sua vez, se funda constitutivamente sob uma relação dialógica com os outros discursos já produzidos no campo, em outra(s) área(s) do saber.

Além dessas palavras introdutórias, o artigo está organizado em duas partes principais: a primeira faz uma reflexão crítica sobre as orientações técnicas dos manuais de metodologia científica no tocante às operações de citação, a partir da 
Linha D'Água (Online), São Paulo, v. 31, n. 1, p. 193-220, jan.-abril 2018

qual, na seção seguinte, mostramos como eles poderiam envolver, neste tipo de abordagem, as questões de responsabilidade enunciativa.

\section{Considerações sobre o papel dos manuais que orientam as operações de citação do discurso de outrem}

A abordagem proposta aqui para as diferentes formas de fazer referência ao discurso de outrem procura distanciar-se da orientação técnica e normativa presente nos manuais de metodologia científica, que, muitas das vezes, constituem o principal suporte para os estudantes no momento de produzir textos acadêmicos solicitados nas diversas disciplinas da graduação. Na verdade, concordando com a posição discutida no trabalho de Bessa (2011), não propomos abandonar o uso dos manuais, mas sim complementar e enriquecer esse tipo de orientação com uma perspectiva que dê conta dos aspectos textuais/discursivos/enunciativos e, portanto, dos efeitos de sentido envolvidos na operação denominada citação. Nesse sentido, nossa proposta também segue na direção do "repensar a citação", abrangendo outros elementos não incluídos na abordagem dos manuais de metodologia científica, nem na NBR 10520 da ABNT, de 2012.

A fim de discutirmos sobre o papel dos manuais de metodologia científica e de outros materiais didáticos que circulam no mercado editorial brasileiro, no tocante ao ensino da citação, fizemos um levantamento - não exaustivo, mas suficientemente representativo - daqueles que abordam o referido mecanismo, como pode ser verificado em Bernardino (2015). Após esse levantamento, constatamos que não são poucos os manuais de metodologia científica que abordam os mecanismos ou "técnicas de citação" em textos acadêmicos.

Entre os 30 manuais consultados, ratificamos como aspecto comum o tratamento da citação pelo viés notadamente técnico e normativo (são os procedimentos técnicos do citar: como se deve fazer, o que se deve evitar), além da orientação de natureza ética destacado em alguns deles (por exemplo, quando apontam à necessidade de manter fidelidade às fontes consultadas, de não omiti-las, de não se apropriar indevidamente de uma ideia alheia, sem dar o devido crédito ao autor, ou seja, de evitar o plágio). Percebemos, também, que ainda é escassa, no mercado 
Linha D'Água (Online), São Paulo, v. 31, n. 1, p. 193-220, jan.-abril 2018

acadêmico brasileiro, a existência de outros materiais, de caráter didático ou não, que se diferenciem de tais manuais em relação ao tipo de tratamento dedicado à citação e seus mecanismos.

Após uma análise qualitativa dos capítulos ou seções sobre citações, constatamos ainda que o foco mais recorrente nesses manuais consiste em conceituar a citação e, em seguida, classificar as formas de citar, com a explicação de seus respectivos procedimentos normativos. Entre um manual e outro, a distinção reside, basicamente, no espaço que ocupa (se é mais detalhada ou muito sintética), já que em termos conceituais todos caminham na mesma dimensão técnica, formal, prescritiva. Esses dados permitem corroborar a observação de Boch e Grossmann (2002), no tocante a "uma falta geral” de ancoragem teórica na apreensão da citação nesse tipo de material, e também a compreensão de Bessa (2011), que destaca o quão é, muitas vezes, "repetitiva e/ou inconsistente" essa "farta literatura" sobre o assunto. A seguir, para efeitos de demonstração, trazemos dois exemplos da análise qualitativa feita.

\section{Exemplo 1}

É fundamental a fidelidade na escrita científica (projeto, monografia, dissertação, tese ou artigo) e em qualquer escrita. Se alguém é ético em sua forma, tem tudo para ser ético na fala e vice-versa.

\section{PEQUENOS SÍMBOLOS DE GRANDE VALOR}

Há, na escrita, além de letras, palavras e sinais, símbolos importantes (caracteres especiais) que também aparecem em publicações:

( Marca registrada

(C) Copyright

${ }^{\text {TM }}$ Marca

Esses símbolos são de proteção da propriedade intelectual de uma marca ou produto de alguém que possui tal registro (pessoa física ou jurídica). É oportuno não omitir tais símbolos. 
Linha D'Água (Online), São Paulo, v. 31, n. 1, p. 193-220, jan.-abril 2018

\section{CITAÇÕES}

Ao usarmos um livro, uma fita cassete, uma fita de vídeo, um disquete, um CD, uma apostila, um panfleto ou qualquer outra forma de material publicado ou gravado, devemos ter o cuidado para não 'roubar' o material de outra pessoa. Há formas legais de fazer referência ao que outra pessoa descobriu, escreveu ou falou. Para se evitar 'infrações' na escrita, deve-se utilizar mecanismos legais de citações, tais como:

1. Citação Formal, Direta ou Transcrição: É a citação onde você transcreve tudo do autor consultado, palavra por palavra.

Aquino (2006), esclarece: "bla, bla, bla, bla" (p. 5).

Esta citação pode ser de dois tipos:

a) Até 3 linhas: utilizar aspas.

Exemplo: Segundo Aquino (2006, p. 23): "As abelhas são criaturas fascinantes. Elas estão presentes na vida do homem desde a antiguidade até os dias modernos."

b) Mais de 3 linhas: não utilizar aspas; utiliza-se uma fonte menor (Tamanho 10), com espaçamento simples e justificado.

Exemplo: Segundo Aquino (2006, p. 23):

As abelhas são criaturas fascinantes. Elas estão presentes na vida do homem desde a antiguidade até os dias modernos. Hoje, mais do que nunca, os produtos das abelhas, especialmente do gênero Apis, fazem parte da dieta do homem. Mel, geleia real, pólen, são utilizados como alimento e complemento alimentar, enquanto a cera o é na indústria de cosméticos e a apitoxina (veneno) e própolis, na farmacologia, isto sem contar com o maior benefício das abelhas para a humanidade: a polinização.

2. Citação Indireta ou Paráfrase: Aqui não precisa de aspas. Você escreve a ideia do autor consultado com suas próprias palavras. Essa é a citação mais comum e o tipo de citação torna seu texto melhor de ler. 
Linha D'Água (Online), São Paulo, v. 31, n. 1, p. 193-220, jan.-abril 2018

\begin{abstract}
Aquino (2006) disse que dos produtos apícolas a polinização é "o maior benefício das abelhas para a humanidade" (p. 5), algo verdadeiro e que aumenta mais a responsabilidade de todos em relação à preservação desses animais.
\end{abstract}

$\mathrm{Na}$ citação Indireta, a paginação, para artigos científicos, pode ser omitida, o que melhora a leitura.

3. Citação de Citação: Este modo de citação é utilizado quando você não tem o artigo em suas mãos. Você menciona determinado autor só pelo fato de tê-lo encontrado em uma referência que está utilizando, então você cita 'José, citado por João'. Utiliza-se a expressão em latim apud para indicar 'citado por'.

Segundo Kerr (1996) apud Aquino (2006), há quatorze motivos para se implantar a meliponicultura.

Este exemplo indica que você está consultando Aquino (2006) e que não dispõe da referência Kerr (1996). Ao utilizar este tipo de citação, deve-se colocar a primeira citação no rodapé da página e a segunda nas Referências Bibliográficas. Não fica elegante um artigo com mais de um caso desses.

Quando há mais de um apud, as pessoas (leitores de seu trabalho) podem ter a impressão de que houve 'preguiça' de sua parte em buscar outras citações. Em relação às normas adotadas para citações em documentos, adota-se a norma padrão NBR 10520 (ABNT, 2002).

AQUINO, I. S. Como escrever artigos científicos: sem "arrodeio" e sem medo da ABNT. São Paulo: Saraiva, 2010. (p. 14-16)

No exemplo acima, é inegável a relevância da orientação voltada a construir o caráter ético do pesquisador, ao ressaltar "o cuidado para não 'roubar' o material de outra pessoa", e ao demonstrar os "mecanismos legais de citações". O foco, como se vê, concentra-se sobre a formação da consciência honesta do pesquisador, já que as orientações procuram evitar que se cometa "infrações" na escrita.

O problema é que a classificação dos tipos de citação ("Formal, Direta ou Transcrição"; "Indireta ou Paráfrase", "Citação Incorporada"; "Citação de Citação") não recobre os mecanismos linguísticos e textuais/discursivos que são necessários quando se mobiliza o discurso de outra pessoa. Assim, por exemplo, ao 
Linha D'Água (Online), São Paulo, v. 31, n. 1, p. 193-220, jan.-abril 2018

denominar o primeiro tipo como "a citação onde você transcreve tudo do autor consultado, palavra por palavra”, o manual limita essa operação à mera transcrição das palavras alheias. Se, por exemplo considerarmos os estudos de Authier-Revuz $(1990,1998)$ sobre as formas de heterogeneidade enunciativa, temos que assimilar que há diferentes formas de relatar ou representar um discurso segundo (discurso direto, discurso indireto, modalização em discurso segundo, evocação, ilhota textual em DI, entre outras), e cada uma delas apresenta características que dizem respeito ao papel do locutor-enunciador (se este faz somente menção ou menção e uso da palavra alheia; se concorda, discorda ou se se mantém neutro), à mensagem (se esta se mantém preservada ou reformulada em relação a sua materialidade significante) e ao segundo locutor-enunciador (se ele falou, de fato, ou foi dado a falar, segundo a subjetividade do primeiro locutor-enunciador; ou se teria falado, hipoteticamente etc.).

Conforme o aporte teórico aqui pressuposto, as aspas é um entre os recursos que sinalizam a heterogeneidade enunciativa, reveladora do fenômeno da modalização autonímica (ADAM, 2011; AUTHIER-REVUZ, 1990, 1998). No excerto em apreciação, tal recurso é denominado apenas em termos de precisar ou não ser utilizado, como está posto no item 2, da "Citação Indireta ou Paráfrase: Aqui não precisa de aspas”. Desse modo, uma reflexão sobre a função das aspas como recurso tipográfico que evidencia, por exemplo, o fenômeno da modalização autonímica não só é importante, mas também necessária, inclusive para compreender isto que o manual designa de "Citação Incorporada".

Vejamos que, no exemplo 1, este tipo de citação foi concebido como algo que resulta da dinamização do parágrafo ao se realizar a paráfrase, o que nos parece bastante vago, além de não fazer qualquer observação sobre o papel das aspas para delimitar as fronteiras entre o discurso citante e o discurso citado, e sinalizar o distanciamento enunciativo.

Essas observações acerca do exemplo 1, além dos muitos outros exemplos que demonstramos em Bernardino (2015, p. 241-252), nos levam a reiterar que a conceituação e o tratamento propostos por muitos manuais de metodologia científica (para não dizermos todos eles), acerca dos mecanismos de citações, ainda se mostram limitados, ou por abordar somente o aspecto ético e legal ( o ter que 
Linha D'Água (Online), São Paulo, v. 31, n. 1, p. 193-220, jan.-abril 2018

citar para evitar infrações na escrita), ou apenas o aspecto técnico e normativo (as regras do citar). Revelam-se também um tanto superficial, por não dar crédito a outras possibilidades de fundamentação teórica, de modo que pudesse ir além da orientação prescritiva da ABNT.

$\mathrm{Na}$ contramão desse tipo de enfoque, já há alguns esforços para traçar contribuições assentadas sob outras perspectivas, como vem sendo demonstrado por autores de materiais que se afastam dessa linha normativa. Em nossa tese doutoral, identificamos e relacionamos oito obras rotuladas, no contexto do nosso trabalho, como "A citação em outros materiais" (Cf. BERNARDINO, 2015, p. 237-240), para destacarmos a distinção e o avanço delas em comparação com os manuais de metodologia que, quando tratam de citação, norteiam-se basicamente nas normas da ABNT 10520.

Observamos que esse conjunto de oito obras considera o aspecto técnico que regula a prática de citar, mas também apoiam-se em perspectivas teóricas de abordagem do gênero, do texto e do discurso, ou do enunciado. É o caso, por exemplo, daquelas que discutem a organização retórica dos gêneros acadêmicos e consideram os postulados teóricos do campo enunciativo sobre as formas de representação da palavra do outro, tal como se pode constatar na obra de Motta-Roth e Hendges (2010, p. 89-93), intitulada Produção textual na universidade.

$\mathrm{Na}$ referida obra, entre outros aspectos, as autoras tratam acerca da revisão de literatura prévia no artigo científico e, também, das citações. Observando o tratamento dado, podemos dizer que a abordagem apresentada por elas tem alcance sobre os aspectos discursivos (por considerar as funções, entre elas a de emprestar uma voz de autoridade), estruturais (por descrever as subseções que compõem a organização retórica da seção de revisão, entre elas a de citar pesquisas prévias, bem como entender, contra-argumentar, criticar), linguísticos (por discutir sobre o papel de diferentes marcadores, entre eles os verbos, os conectivos etc.), normativos (por considerar a configuração técnica das citações e suas formas de inserção no texto, conforme a ABNT) e éticos (por recomendar que se tome "cuidado para não plagiar a ideia dos textos consultados, 'esquecendo' de fazer a devida referência" (MOTTA-ROTH; HENDGES, 2010, p. 109). O exemplo 2, reproduzido abaixo, 
Linha D'Água (Online), São Paulo, v. 31, n. 1, p. 193-220, jan.-abril 2018

distancia-se, em parte, do enfoque meramente técnico visto no exemplo 1, mas, como veremos, não chega a contemplar todos esses aspectos aqui em destaque.

\section{Exemplo 2}

\section{Algumas dicas sobre bibliografia e citações}

\section{PARA COMEÇAR A CONVERSA...}

Nesta seção, veremos, de maneira breve, alguns procedimentos para fazer citações e para indicar a bibliografia ou referências bibliográficas usadas no seu trabalho.

\section{Leia mais baixo trechos1 do projeto que você leu na seção 6. Observe como os} autores são citados no corpo do texto e assinale as opções corretas.

( ) os nomes das obras aparecem nas citações.

( ) alguns verbos (colocar, por exemplo) ou palavras introdutórias (segundo) são usados para introduzir a voz de outros autores.

( ) todas as citações são copiadas da obra de base.

( ) quando o autor citado vem ao longo do texto, o ano da obra citada vem entre parênteses.

( ) várias obras são citadas no mesmo parênteses.

( ) o autor citado e o ano da obra vêm entre parênteses.

( ) poucas citações são cópias da obra de base e, quando é o caso, elas vêm entre aspas, com a página em que podem ser encontradas.

a) Segundo Saujat $(2004,2003)$, existe uma tradição de pesquisa sobre o professor, mas não sobre o seu trabalho.

b) Entretanto, nos últimos anos, têm aparecido estudos que colocam que é preciso “construir um ponto de vista mais integrativo, interacionista, capaz de melhor empreender a complexidade e a multidimensionalidade das práticas educacionais” (Saujat, 2004: 19).

c) Fazendo uma análise de base ergonômica, mas já aliado a profissionais de diferentes áreas, Amigues $(2002,2004)$ mostra que o trabalho do professor é bem mais complexo, indo além de uma mera relação só com o aluno ou só com um conteúdo a ser transmitido. 
Linha D'Água (Online), São Paulo, v. 31, n. 1, p. 193-220, jan.-abril 2018

d) Ao verificarmos as teorias que subjazem aos estudos que consideram a relação linguagem e trabalho, notamos que existe uma boa discussão sobre o contexto de trabalho e suas prescrições (Amigues, 2002, 2004), sobre os gêneros profissionais/da atividade que são gerados em cada situação de trabalho (Faita, 2004) ou sobre o desenvolvimento do trabalhador durante o trabalho (Clot, 2004b).

$[\ldots]$

\section{CONLUINDO...}

Complete o quadro abaixo com o que você aprendeu nesta seção.

Na seção de Referências Bibliográficas devemos mencionar

Já na bibliografia, podemos

Para fazer citações no corpo do texto, devemos

A ordem dos conteúdos nas Referências Bibliográficas segundo a ABNT é

1. Bueno, L. 2005. Projeto para pesquisa de doutorado.

MACHADO, A. R. (coord.); LOUSADA, E.; ABREU-TARDELLI, L. S. Planejar gêneros acadêmicos. São Paulo: Parábola Editorial, 2005. (p. 89-93)

Nesse caso, há uma sutil distinção em relação ao exemplo 1, pelo fato de o exemplo 2 permitir ao pesquisador iniciante compreender os mecanismos de citação na materialidade dos gêneros acadêmico-científicos, sendo isso feito a partir da realização de exercício. Todos os aspectos da produção dos gêneros abordados na obra seguem a proposta de levar o estudante a construir os conceitos à medida que pratica a análise de fragmentos de textos e responde a diversas questões. Esse caráter mais interativo pode mostrar-se bem mais atraente para o estudante, já que o coloca diante de situações de análise de fragmentos do texto acadêmico.

Em contrapartida, no caso específico da citação, tratam-se apenas de "algumas dicas” e que figuram em uma única questão do exercício proposto. Das cinco 
Linha D'Água (Online), São Paulo, v. 31, n. 1, p. 193-220, jan.-abril 2018

questões acerca dos "procedimentos para fazer citações e para indicar a bibliografia ou referências bibliográficas", somente a que mostramos no exemplo acima contempla a citação, enquanto as demais exploram com mais detalhes as normas para montar as referências no trabalho acadêmico.

No excerto, merece destaque uma das alternativas da questão 1 , em que o estudante tem a oportunidade de observar, nos exemplos fornecidos pelo manual, que (ou se) "alguns verbos (colocar, por exemplo) ou palavras introdutórias (segundo) são usadas para introduzir a voz de outros autores”. Vemos aí uma ligeira investida no estudo de marcas linguísticas que sinalizam a introdução da voz alheia no texto acadêmico. Entretanto, é pequena a atenção destinada a esse aspecto, pois todos os outros itens exploram bem mais as questões técnicas e, assim, acabam exibindo o mesmo tipo de tratamento do exemplo anterior.

\section{Apontamentos para um tratamento textual/discursivo das operações de citação}

Tendo em vista os exemplos 1 a 2 analisados na seção anterior, observamos, então, que há a necessidade de se investir em um tipo de tratamento da citação que avance tanto quanto possível. Em outros termos, que seja condizente com a natureza dos gêneros acadêmicos, em seus aspectos linguísticos, textuais, discursivos e enunciativos. Nesse sentido, os manuais poderiam revestir-se, também, de uma abordagem teórica advinda do campo dos estudos linguísticos do texto, do discurso, dos gêneros e que, ao serem mediados pela análise de exemplares concretos de gêneros acadêmicos, possibilitem tratar de aspectos como:

a) os diferentes tipos de representação de fala, como marcadores da responsabilidade enunciativa (cf. ADAM, 2011), ou formas de referir-se ao discurso do outro, ou formas de discurso citado, de discurso relatado/representado, de heterogeneidade mostrada (cf. BAKHTIN, 2006; MAINGUENEAU, 1996; AUTHIER-REVUZ, 1990, 1998), o que caberia tratar das diferentes operações ou estratégias linguísticas (recursos tipográficos, verbos dicendi, elementos introdutores, entre outros). Por meio dessa categoria, é possível colocar 
Linha D'Água (Online), São Paulo, v. 31 , n. 1, p. 193-220, jan.-abril 2018

em destaque para o pesquisador iniciante o como relatar o discurso do outro em textos acadêmicos dos mais diversos.

b) o fenômeno do mediativo - MED (cf. GUENTCHÉVA, 1994), também denominado como indicações de quadros mediadores (ADAM, 2011). Já que é tão comum na escrita acadêmica, as formas como segundo, de acordo com, conforme, para, entre outras, logo poderiam figurar nos manuais como marcas linguísticas que imputam o conteúdo relatado a uma determinada fonte do saber, a outro locutor-enunciador ou a uma fonte anônima. Essa categoria oferece meios para se discutir como falar segundo o outro, ou seja, como proferir um enunciado mediado por outras fontes enunciativas.

c) os fenômenos de modalização autonímica (cf. AUTHIER-REVUZ, 1990, 1998). Mesmo sem empregar a terminologia mais densa dos estudos enunciativos, é possível assimilar e contemplar ao menos o papel dos principais recursos tipográficos (as aspas, por exemplo) e das marcas linguísticas que atestam o descentramento do sujeito-autor, de sua voz, e que revelam a reflexividade metaenunciativa. Os quatro pontos de não coincidências do dizer (a não coincidência interlocutiva; a não coincidência do discurso consigo mesmo; a não coincidência entre as palavras e as coisas; a não coincidência das palavras com elas mesmas), podem ser abordados, por exemplo, como maneiras de sinalizar a heterogeneidade enunciativa, sendo possível conduzir o pesquisador iniciante a pensar sobre como comentar reflexivamente sua própria fala, seu próprio discurso.

d) os tipos de posicionamento passíveis de serem emitidos pelo locutor-enunciador ou as posturas enunciativas (cf. RABATEL, 2009; 2016). Se as demais categorias acima mencionadas permitem construir contextos de imputação no texto acadêmico-científico, ou seja, atribuir a responsabilidade pelo conteúdo de um PdV a outros locutores-enunciadores, é preciso que o pesquisador iniciante saiba como tomar uma posição no discurso (seja de acordo, de desacordo ou a "neutralidade") e ter consciência sobre o que isso implica para os sentidos do texto, para a construção da autoria e, consequentemente, para a produção do conhecimento científico. 
Linha D'Água (Online), São Paulo, v. 31, n. 1, p. 193-220, jan.-abril 2018

Essas categorias linguísticas, entre muitas outras funções, servem de base para os manuais de metodologia científica e, em decorrência, para o professor em sala de aula auxiliar o pesquisador iniciante na atividade de citar, de gerenciar as vozes no texto, de posicionar-se em relação ao conhecimento já produzido e de se constituir como autor de uma voz própria. Além disso, tais categorias podem ancorar uma discussão sobre a ética na pesquisa científica, especialmente sobre o problema do plágio em textos acadêmicos, sendo isto por um viés menos punitivo e mais pedagógico, como sugere Bessa (2014, p. 116), ao argumentar em favor de “cultura de ética e de integridade do pesquisador em formação inicial”. A título de demonstração, no exemplo 3 a seguir, mobilizamos marcas linguísticas da responsabilidade enunciativa e, em seguida, fazemos nossas considerações interpretativas, em função do propósito deste trabalho.

\section{Exemplo 3}

\section{O papel da recategorização na reconstrução de sentidos da memória social de Lampião}

Para entender o fenômeno da recategorização, primeiro é necessário que se compreenda o que é categorizar, pois este pressupõe aquele, e, nesse aspecto, a relação entre categorização e recategorização é intrínseca. Segundo o dicionário Houaiss, categorizar pode significar: dispor em categorias, classificar. Assim sendo, a atividade discursiva qualifica os referentes de modo a enquadrá-los em determinada posição semântica que melhor corresponda ao pensar do sujeito do discurso, dito de outra maneira, os referentes são postos em blocos classificatórios por esses sujeitos, onde essa classificação depende da relação do sujeito com seu(s) referente(s), e da relação do sujeito com a memória social, com a cultura.

Dessa maneira, para Mondada e Dubois (2003), a categorização de referentes representa o resultado de atividades práticas que compreendam discussões, controvérsias, desacordos. Essas categorias estão situadas nas práticas sociais, que para as autoras citadas, são "práticas dependentes tanto de processos de enunciação como de atividades cognitivas não necessariamente verbalizadas; práticas do sujeito ou de interaçôes em que os locutores negociam uma versão provisória, contextual, coordenada do mundo" (2003, p.29). 
Linha D'Água (Online), São Paulo, v. 31, n. 1, p. 193-220, jan.-abril 2018

Desse modo, para as autoras há uma relação instável entre as coisas e as palavras. E essa inconstância se deve à compreensão intersubjetiva das atividades cognitivas. Fazer tal afirmação é dizer que a instabilidade das categorizaçôes das coisas está ligada às volubilidades semânticas produzidas pelos sujeitos do discurso. Destarte, os objetos de discurso emergem, então, de práticas simbólicas que tendem a andar em cadeias categóricas oscilantes. A categorização funciona, dessa maneira, de acordo com as intenções do interlocutor.

Cód.: (Ac01, 2012, pp. 222- 223)

*Negrito acrescentado para fins de análise das marcas de responsabilidade enunciativa

Nesse recorte de um dos artigos que constituiu o corpus de nossa tese de doutorado, destacamos, primeiramente, como exemplo de responsabilidade enunciativa um ponto de não-coincidência das palavras com elas mesmas. A expressão "dito de outra maneira" projeta no texto a figura de um L1/E1 tentando controlar o dizer, na busca pela melhor nomeação, por precisão e clareza do sentido. Como se pode observar, o PdV que discorre sobre o fenômeno da referenciação e sobre como a atividade discursiva organiza/classifica os referentes em categorias foi atribuído a e2, ou seja, imputado a outra fonte enunciativa por meio de expressão indicadora de um quadro mediador ou mediativo - MED, nos termos como concebe Adam (2011) e Guentchéva (1994), especificamente em: "Segundo o dicionário Houaiss". Porém, exatamente por trabalhar metalinguisticamente para que o sentido fique claro, L1/E1 demonstra o seu comprometimento com o conteúdo relatado, assumindo, juntamente com o e2, pela interpretação posta em relação ao que seja "categorizar" por meio da atividade discursiva.

No excerto em questão, há ainda duas marcas de imputação de PdV. A primeira, em "para Mondada e Dubois (2003)", corresponde à indicação de MED, mostrando que são estas autoras quem se responsabilizam pela afirmação de que "a categorização de referentes representa o resultado de atividades práticas que compreendam discussões, controvérsias, desacordos". A segunda ocorre no trecho destacado entre aspas, seguido do introdutor "para as autoras citadas". Esta ocorrência de imputação de $\mathrm{PdV}$, embora esteja introduzida com a mesma marca de mediativo "Para", apresenta uma estrutura semelhante à de discurso direto, mas não com todos os elementos comumente verificados nesse tipo de operação. 
Linha D'Água (Online), São Paulo, v. 31 , n. 1, p. 193-220, jan.-abril 2018

Observa-se que, semelhante ao discurso direto, há também a ruptura sintática, a fonte enunciativa é um e2, L1/E1 faz o uso de suas palavras no sintagma introdutor e há a mostração das palavras alheias. Todavia, o introdutor empregado (que corresponde ao grupo preposicional "para as autoras citadas") está ocupando o lugar que caberia a um verbo de atribuição de fala, o que resultaria em algo como: $[. .$.$] as autoras citadas afirmam: " X$ " ou as autoras citadas afirmam que " $X$ ".

Em nossos dados da tese de doutorado, decorrentes da análise de oito artigos científicos do pesquisador iniciante, publicados em um periódico da área de Letras, foi bastante frequente o uso de marcas linguísticas comumente reconhecidas como sendo de indicações de quadro mediadores para introduzir o que seria um discurso direto, em sua forma integrada ao texto, marcada pelas aspas, ou recuada.

Por um lado, o exemplo visto em 3 representa claramente um caso atípico de discurso direto, em que faltaria adequar o elemento introdutor; mas, por outro lado, o pesquisador iniciante estaria procedendo em uma materialização diferenciada do valor mediativo, pois, ao invés de relatar o conteúdo do PdV segundo um autor $X$ ou $Y$, usando suas próprias palavras e estabelecendo o equivalente semântico às palavras de e2, L1/E1 as reproduz literalmente (uso de palavras próprias no sintagma introdutor e menção, mostração das palavras relatadas), sendo o porta voz fiel do que disse e2 em outro momento, como ocorre no discurso direto.

Em outra possibilidade, caberia o ajuste para o que Authier-Revuz (1998, p. 142) denomina de modalização em discurso segundo sobre as palavras, o que resultaria na marca linguística "segundo as palavras das autoras citadas: "X", configurando, então, um caso de modalização autonímica.

Seja uma situação de discurso direto sintaticamente distinta daqueles traços linguísticos descritos, por exemplo, nas reflexões teóricas feitas por Maingueneau (1996), precisamente em relação ao uso de verbos introdutores de discurso citado, seja de uma manifestação de mediativo em que falta o trabalho de paráfrase do conteúdo relatado, o pesquisador iniciante parece exibir a dificuldade de reconhecimento dos diferentes tipos de representação de fala e dos efeitos de sentido que eles suscitam no seu texto.

Sem dúvida, como defendemos em nosso trabalho doutoral (BERNARDINO, 2015), as mesmas marcas linguísticas não indicam com o mesmo grau, nem 
Linha D'Água (Online), São Paulo, v. 31, n. 1, p. 193-220, jan.-abril 2018

com o mesmo efeito de sentido, a responsabilidade pelo conteúdo dos enunciados. E são exatamente essas "pequenas" nuances que faltam a um tratamento menos técnico, quando do tratamento ou do ensino das chamadas operações de citação, em particular nas práticas de ensino de textos na universidade.

Não estamos sugerindo, em casos como mostram o exemplo 3, a orientação para a mera alternância de uma marca linguística por outra, mas defendendo a necessidade do saber sobre o modo como as marcas linguísticas afetam o texto em termos de assinalar o engajamento, ou não, do locutor-enunciador primeiro, o L1/ E1. No ato da escrita, ao menos em sua verbalização inicial, o autor/produtor do texto não pensa sobre essas questões; todavia, o domínio da metalinguagem, após instrução sistematizada, pode conduzi-lo a um trabalho reflexivo sobre o uso das operações sintáticas e textuais/discursivas para realizar a gestão dos PdV.

É claro que, em razão da filiação teórica assumida neste trabalho, nos compete destacar que esse saber coloca o locutor-enunciador no âmbito de uma dupla projeção da imagem do sujeito: por um lado, ele pode situar-se no nível consciente, ao mostrar-se controlando seu próprio dizer e os efeitos de sentido; por outro, ele situa-se no nível do inconsciente, porque é apenas na aparência, na superfície do dizer, que o sujeito negocia as palavras e os sentidos com o outro que lhe atravessa constitutivamente.

Ainda em 3, vemos que, mesmo se pronunciando em terceira pessoa do singular, o locutor-enunciador do artigo emite um julgamento favorável em relação ao PdV imputado a e2, quando diz: "Fazer tal informação é dizer que a instabilidade das categorizações das coisas está ligada às volubilidades semânticas produzidas pelos sujeitos do discurso." Com essa declaração, L1/E1 elucida, em seu próprio ato de enunciação, o que seria, "para as autoras", "a relação instável entre as coisas e as palavras". Posteriormente, os elementos coesivos "Destarte", "então" e "dessa maneira" sugerem que L1/E1 conclui a "afirmação" das autoras, fazendonos entender que se trata de um conceito teórico assumido no seu artigo científico. É nesse sentido que observamos, em diversificados pontos do artigo analisado, a adesão ao conteúdo proposicional dos $\mathrm{PdV}$ imputados a outrem.

Essa breve demonstração de uma análise dos movimentos do pesquisador iniciante em relação ao conteúdo de $\mathrm{PdV}$ de outrem, mobilizados na seção teórica 
Linha D'Água (Online), São Paulo, v. 31, n. 1, p. 193-220, jan.-abril 2018

de seu artigo científico, via operações de citação, permite vislumbrar possibilidades de ampliação das bases conceituais para um tratamento mais adequado da citação. Ao orientar pesquisadores para a prática do citar, além de abarcar o respaldo ético, moral, legal e de considerar as normas da ABNT, como muito bem já fazem, os manuais de metodologia científica poderiam assimilar, também, postulados teóricos das abordagens textual, discursiva e enunciativa. As consequências dessa abertura resultariam em orientações mais pontuais para os estudantes, de todas as áreas do conhecimento, e em suporte teórico-pedagógico para os professores da graduação também poderem contribuir ainda mais com a formação desses pesquisadores.

Sugerimos, além disso, que disciplinas específicas sobre a produção de textos acadêmicos também possam tratar desse mecanismo de maneira mais sistematizada. Na realidade, a ausência de algum tipo de abordagem sobre a temática da citação na graduação já se estabeleceu como uma queixa comum nas pesquisas da área, sobretudo por pesquisadores que fazem crítica ao viés puramente normativo e instrumental. Citemos, como exemplo, o trabalho de Macedo e Pagano (2011), que, ao comparar o uso da citação na escrita acadêmica de membros novatos e membros expertos, sob a perspectiva teórica de estudos dos gêneros de discurso, conclui que, majoritariamente, o papel da citação nos corpora analisados "é o de corroborar e fundamentar a ideia/informação do escritor de maneira positiva, de modo a evitar o confronto com a autoridade - com o autor citado" (p. 283).

Discutindo sobre o impacto desse resultado para a área da Linguística e da Linguística Aplicada, as autoras sugerem que seja levado em consideração o fato de as citações negativas (o autor "coloca em xeque a obra citada") e as citações justapostas (o "texto que cita apresenta uma alternativa à obra citada") serem pouco recorrentes nesses corpora. Ao final de suas reflexões, elas lançam mão do argumento que aqui nos interessa:

Disciplinas sobre escrita acadêmica baseadas na abordagem de gêneros do discurso poderiam auxiliar o aluno a compreender como os textos escritos são construídos, produzidos e legitimados em sua comunidade discursiva. A análise de citações, que poderia fazer parte das discussões ocorridas nessas disciplinas, precisa ter como elemento norteador o fato de as citações estarem presentes em gêneros do discurso amplamente utilizados na comunidade acadêmica. As características específicas desses gêneros e as relações sociais envolvidas na sua produção e 
Linha D'Água (Online), São Paulo, v. 31 , n. 1, p. 193-220, jan.-abril 2018

utilização acabam por definir o papel das citações presentes nos diversos gêneros do discurso. (MACEDO; PAGANO, 2011, p. 285).

Trazendo essa questão para o contexto da reflexão aqui esboçada, cumpre destacar como observação relevante no que se refere ao manejo de $\mathrm{PdV}$ alheios e à assunção, ou não, do conteúdo proposicional desses $\mathrm{PdV}$ por parte daquele que os cita, a necessidade de articulação entre a abordagem das formas de discurso citado e o gênero acadêmico que se pretende trabalhar. Esse cuidado impõe-se porque o modo como o autor dialoga com os autores citados não é necessariamente idêntico em todos os gêneros acadêmico-científicos. $\mathrm{O}$ papel que o autor de um texto-fonte resumido ocupa é distinto, por exemplo, do papel ocupado por um conjunto de autores citado na revisão de literatura presente no artigo científico, na monografia, na dissertação, na tese etc.

No primeiro caso, se se trata de um resumo acadêmico, do tipo informativo (SILVA, 2012b), as ideias do autor-fonte são relatadas para compor a síntese, sem que precise ficar evidenciado o posicionamento do autor do resumo (a este cabe selecionar e articular as informações principais, de forma que permita a compreensão global do texto-fonte). Logo, o autor-fonte ocupa toda a cena do texto, pois suas ideias são o foco. Já no segundo caso, há muito mais do que o ato de relatar/ sintetizar informações de outrem: é preciso selecionar, relacionar, articular, posicionar-se, contra-argumentar, apontar lacunas e propor soluções, quando for conveniente, ou seja, aquele que gerencia as vozes alheias também precisa evidenciar seu próprio posicionamento.

É por essa razão que destacamos a importância de se conhecer as características e convenções dos gêneros acadêmicos, incluindo aí os efeitos de regulação que estes exercem sobre a construção dos enunciados (ADAM, 2011) e as imposições do próprio campo científico em relação aos padrões já legitimados, às condições e critérios de êxito, ao discurso autorizado, entre outros aspectos (BAKHTIN, 2011; MAINGUENEAU, 2008). Tendo isto em conta, o professor pode partir para a exploração das diversas características linguísticas das formas de citação (verbos introdutores, recursos tipográficos, grupos preposicionais, modalizadores e muitos outros), seja como conteúdo programático de alguma disciplina específica da 
Linha D'Água (Online), São Paulo, v. 31, n. 1, p. 193-220, jan.-abril 2018

graduação, seja como aspecto a ser observado e destacado durante o processo de orientação e avaliação da produção de textos/gêneros.

Conforme os postulados da ATD, especialmente no que refere ao nível da enunciação e coesão polifônica, os tipos de representação da fala situam-se entre uma das oito categorias que assinalam a responsabilidade enunciativa. As marcas linguísticas utilizadas para empregar cada tipo sugerem que o locutor-enunciador não é a fonte do $\mathrm{PdV}$ e, por isso, atribui a responsabilidade enunciativa a um segundo enunciador. Quando considerada a relação com o co(n)texto, percebemos que há, entre outras, a possibilidade de retomada do conteúdo do $\mathrm{PdV}$, com expressão de um posicionamento favorável pelo primeiro locutor-enunciador ou a postura de co-enunciação (RABATEL, 2009; 2016), o que configura a responsabilização compartilhada (isto é, L1/E1 co-enuncia o PdV com e2) e institui a afirmação/ reafirmação da autoridade do discurso citado.

Esse é um dos aspectos que podem ser discutidos em manuais que orientam a citação e, também, em sala de aula, em atividades de produção, análise, avaliação e reescrita de textos acadêmicos, se o objetivo for abordar a citação para além dos modelos padronizadores já comumente disponíveis na abordagem técnica e normativa. Assim, supõe-se que o pesquisador experiente, materializado na figura do professor que conduz, orienta e avalia a produção do aluno ainda iniciante na pesquisa científica, possa ter condições de atentar para as estratégias textuais/discursivas empregadas, com vistas a auxiliar na resolução das dificuldades ou problemas mais comuns, tais como:

- O desconhecimento da variedade de formas de se reportar ao discurso alheio ou o manejo inapropriado delas. Isso é visível, por exemplo, quando o aluno emprega um introdutor de discurso indireto (Xafirma que...) ou de modalização em discurso segundo/mediativo (Segundo $X, \ldots$ ), mas não pratica adequadamente a paráfrase das informações relatadas, fazendo reformulações mínimas no texto-fonte (apenas a substituição de um termo ou outro), o que pode se configurar como uma "paráfrase quase textual que evita o plágio", como demonstramos em Bessa, Bernardino e Nascimento (2012), tendo apoio nas 
Linha D'Água (Online), São Paulo, v. 31, n. 1, p. 193-220, jan.-abril 2018

reflexões de Eco (1991). Casos assim são bem frequentes na graduação, quando o aluno ainda está iniciando sua experiência no meio acadêmico;

- O não reconhecimento dos efeitos de sentido suscitados por determinadas marcas linguísticas, quando estas são utilizadas para delimitar as fronteiras entre o discurso citante e o discurso citado. Assim, por exemplo, pode ocorrer de os autores não saberem manipular conscientemente algumas marcas linguísticas, ficando em evidência que nem sempre distinguem os introdutores típicos de representação de fala (discurso relatado) do fenômeno do mediativo (que ancora o dizer numa mediação epistêmica ou perceptiva) e menos ainda dos fenômenos de modalização autonímica (discurso autorrepresentado, metaenunciação);

- A atribuição equivocada de certas palavras ou intenções a autores, sem que isto diga respeito ao conteúdo do texto-fonte citado, que, de certo, foi mal compreendido no ato da leitura. Neste caso, atribui-se indevidamente, por falha de interpretação, a responsabilidade enunciativa pelo conteúdo de um PdV a uma dada fonte ou autor;

- O apagamento da voz autoral, devido a uma listagem de discursos citados, sem que se evidenciem indícios de um posicionamento enunciativo que culmine na contribuição pessoal para a área a que se insere o autor do texto. Esse tipo de problema é mais agravado quando a listagem de citações ocupa não só a maior parte do artigo científico (e de outro gênero) como também se sobressai em relação à própria argumentação do autor;

- A apropriação indevida do discurso alheio sem a menção da fonte, sem a indicação de aspas, ou por desconhecimento das convenções da escrita acadêmica e, consequentemente, das formas de citação, ou por desconhecimento das regulamentações de natureza ética relativas à prática da pesquisa científica, ou por outras razões que motivam o plágioº ${ }^{2}$ Em relação ao manejo de certas marcas linguísticas da responsabilidade enunciativa, falamos em uso

2 A obra de Krokoscz (2012), dedicada inteiramente a discutir autoria e plágio no meio acadêmico, aponta seis motivos pelos quais o plágio acontece: 1) razão acidental (desconhecimento técnico); 2) facilidade de acesso à informação eletrônica (Internet) e de uso de recursos de edição de texto; 3) falta de tempo; 4) dificuldade de escrita acadêmica e hábito de reprodução textual; 5) interesse em aumentar o número de publicação; 6) falta de ética (ver p. 22-32). 
Linha D'Água (Online), São Paulo, v. 31 , n. 1, p. 193-220, jan.-abril 2018

desonesto de um PdV alheio, quando, por exemplo, um pesquisador que já não desconhece as formas de citar introduz no seu texto um elemento linguístico indicador de DI ( $X$ afirma que) ou de mediativo (Segundo X) para camuflar, intencionalmente, a colagem das palavras alheias e driblar o leitor.

É em razão dessas e de outras questões problemáticas concernentes à prática do citar no texto acadêmico-científico que apostamos na utilidade prática da noção de responsabilidade enunciativa, adotada neste trabalho, a partir do quadro teórico da ATD (ADAM, 2011), pois nos parece ser bastante benéfico instruir os alunos, tão logo iniciem sua trajetória acadêmica, a saber dialogar com o conhecimento científico já produzido. Nesse sentido, os movimentos da (não) assunção pelo conteúdo de determinado $\mathrm{PdV}$, a imputação de $\mathrm{PdV}$ a outrem, a possibilidade de "neutralização" do dizer, a tomada de posição no discurso, e, além desses, as formas de introduzir e de retomar o discurso do outro no fio textual (Cf. BESSA, 2007) são elementos que podem ser ricamente explorados com a finalidade de orientar o uso dos diversos mecanismos linguísticos de citação.

Quanto aos fenômenos de modalização autonímica, as estratégias linguísticas assumem a dimensão da metadiscursividade, isso porque não se trata de citação em sentido estrito, representação ou relato de um discurso alheio, mas sim de uma autorrepresentação do próprio discurso, é o comentário reflexivo de si mesmo, revelando a relação do sujeito com a linguagem (AUTHIER-REVUZ, 1998). Por terem essa característica e se inscrever no campo da alteridade enunciativa, os fenômenos de modalização autonímica também são passíveis de contribuir para as atividades de ensino de textos acadêmico-científicos, especialmente quando se pretende desenvolver a consciência metalinguística e metaenunciativa daquele que gerencia as vozes no texto.

As aspas e o itálico são alguns dos sinais tipográficos indicadores do desdobramento metaenunciativo. $\mathrm{Na}$ materialidade do texto acadêmico-científico, muitas outras marcas linguísticas assinalam esse fenômeno e evidenciam a adesão ou o distanciamento do locutor-enunciador em relação ao conteúdo do PdV. Assim, é sugestivo para o trabalho didático a abordagem teórica do apanhado de formas de manifestação do fato autonímico, abrangendo suas características formais e os 
Linha D'Água (Online), São Paulo, v. 31, n. 1, p. 193-220, jan.-abril 2018

efeitos de sentido que suscitam em termos de demarcar a (não) assunção da responsabilidade enunciativa em textos acadêmico-científicos.

A função prática da abordagem dos fenômenos de modalização autonímica na graduação é instruir o pesquisador iniciante para o saber (ou tentar) manipular o sentido de suas próprias palavras, seja colocando estas palavras na relação com o outro para quem o dizer se dirige (não coincidência interlocutiva), com o outro que lhe atravessa constitutivamente (não coincidência do discurso consigo mesmo), com o real a ser capturado, nomeado (não coincidência entre a palavras e as coisas), com o seu próprio sentido (não coincidência das palavras com elas mesmas).

\section{Considerações finais}

Por necessidade de adequação ao espaço deste texto, não pudemos apresentar um nível de detalhamento do tipo de orientação didático-metodológica aqui defendida. Nosso propósito foi colocar em discussão alguns caminhos para complementar e avançar em relação à orientação técnica e normativa no tocante ao diálogo com o discurso do outro em textos acadêmico-científicos. Mostramos como diferentes mecanismos linguísticos (tipos de representação da fala, indicações de quadro mediadores, fenômenos de modalização autonímica, e, em decorrência, podendo-se estender a outros tantos elementos, tais como a natureza de verbos introdutores de citações, elementos de retomada) podem ser explorados ao se tratar de citação em textos acadêmico-científicos, sendo isso situado em um quadro teórico-conceitual que leve em conta os gêneros, os sujeitos e sua relação com o contexto de produção do saber, nas diferentes áreas.

\section{Referências}

ADAM, J. M. A linguística textual: uma introdução à análise textual dos discursos. Tradução de Maria das Graças Soares Rodrigues, Luis Passeggi, João Gomes da S. Neto e Eulália Vera Lúcia Fraga Leurquin. Revisão Técnica: João Gomes das S. Neto. 2 ed. revisada e aumentada. São Paulo: Cortez, 2011. 
Linha D'Água (Online), São Paulo, v. 31, n. 1, p. 193-220, jan.-abril 2018

ASSOCIAÇÃO BRASILEIRA DE NORMAS TÉCNICAS. NBR 10520: informação e documentação: citações em documentos: apresentação. Rio de Janeiro, 2002.

AUTIHIER-REVUZ, J. Heterogeneidade(s) enunciativa(s). Tradução de Celene M. Cruz e João Wanderley Geraldi. Cadernos de Estudos da Linguagem. Capinas, n. 19, p. 25-42, jul./dez. 1990. Disponível em: <http://revistas.iel.unicamp.br/index.php/cel/article/view/3012>. Acesso em 18 dez. 2012.

Palavras incertas: as não-coincidências do dizer. Tradução de Claudia R. Castellanos Pfeiffer, et al. Revisão técnica da tradução Eni Pulccinelli Orlandi Campinas: Ed. da UNICAMP. 1998.

BERNARDINO, R. A. S. A responsabilidade enunciativa em artigos cientificos de pesquisadores iniciantes e contribuições para o ensino da produção textual na graduação. 2015.286 f. Tese (doutorado) - Universidade Federal do Rio Grande do Norte. Programa de Pós-graduação em Estudos da linguagem. Natal, RN, 2015. (Apoio CAPES).

BAKHTIN, M. Estética da criação verbal. Tradução de Paulo Bezerra. 6. ed. São Paulo: Martins Fontes, 2011. (Original russo 1979).

. (VOLOCHÍNOV, V. N.). Marxismo e filosofia da linguagem. 12. ed. Tradução de Michel Lahud e Yara Frateschi Vieira. São Paulo: Hucitec, 2006. (Original russo 1929).

BESSA, J. C. R. Referência ao discurso do outro: uma análise de problemas de relações de sentido entre discurso citado direto e discurso citante no gênero monográfico. 110 f. Dissertação (Mestrado em Estudos da linguagem) - Universidade Federal do Rio Grande do Norte, Natal, 2007.

. (Re)pensando a citação em textos acadêmico-científicos. Signum: Estud. Ling., Londrina, n. 14/2, p. 421-439, dez. 2011. Disponível em: <http://www.uel.br/revistas/uel/index.php/ signum/article/view/8832/9578>. Acesso em: 20 jul. 2015.

. Por uma cultura de ética e de integridade do pesquisador em formação inicial. Revista Espaço acadêmico, n. 159, p. 114-121, ago. 2014. Disponível em: <http://www.periodicos.uem.br/ ojs/index.php/EspacoAcademico/article/view/24294/13308>. Acesso em: 29 set. 2015.

BERNARDINO, R. A. S.; NASCIMENTO, I. A. de A. A citação na escrita acadêmico-científica de estudantes universitários: da paráfrase ao plágio. Encontros de Vista, n. 2, 
Linha D'Água (Online), São Paulo, v. 31, n. 1, p. 193-220, jan.-abril 2018

p. 1-8, jan./jun. 2012. Disponível em: < http://www.encontrosdevista.com.br/Artigos/A\%20cita\%C3\%A7\%C3\%A3o\%20na\%20escrita\%20academica.pdf>.

BOCH, F.; GROSSMANN, F. Referir-se ao discurso do outro: alguns elementos de comparação entre especialistas e principiantes. Tradução Maria de Lourdes Meirelles Matêncio. Scripta, Belo Horizonte, v. 6, n. 11, p. 97-108, 2o sem, 2002. Disponível em: <http://www.ich.pucminas.br/cespuc/Revistas_Scripta/Scripta11/Conteudo/N11_Parte01_art07.pdf>. Acesso em: 11 mar. 2014.

FOUCAULT, M. O que é um autor? Tradução de António Fernando Cascais e Eduardo Cordeiro, 8 ed. Nova Veja, Limitada, 2012.

GUENTCHÉVA, Z. Manifestations de la catégorie du médiatif dans temps du français. Langue Française. n. 102,1994, p. 8-23.

KROKOSCZ, M. Autoria e plágio: um guia para estudantes, professores, pesquisadores e editores. São Paulo: Atlas, 2012.

MACEDO, T. S.; PAGANO, A. S. Análise de citações em textos acadêmicos escritos. DELTA [online]. v. 27, n. 2, 2011, p. 257-288. Disponível em: <http://www.scielo.br/pdf/delta/v27n2/ a04v27n2.pdf>. Acesso em: 25 set. 2014.

MAINGUENEAU, D. Elementos de Linguistica para o texto literário. Tradução de Maia Augusta Bastos de Mattos. São Paulo: Martins Fontes, 1996. (Original francês 1986).

Análise de textos de comunicação. Tradução de Cecília P. de Sousa-e-Silva, Décio Rocha. 5 ed. São Paulo: Cortez, 2008. (Original francês 1998).

MOTTA-ROTH, D.; HENDGES, G. H. Produção textual na universidade. São Paulo: Parábola Editorial, 2010.

RABATEL, A. Prise em charge et imputation, ou la prise em charge à responsabilité limitée... Langue Française - La notion de prise em charge em linguistique, n. 162, jun, 2009, p. 3-27.

Homo narrans. Por uma abordagem enunciativa e interacionista da narrativa. Vol. 1. Trad_M. das G. S. Rodrigues, L. Passeggi e J. G. da Silva Neto. São Paulo: Cortez, 2016.

SILVA, E. M. (Org.). Professora, como é que se faz? Campina Grande: Bagagem, 2012a.

BERNARDINO, R. A. S. Responsabilidade enunciativa em textos acadêmico-cientíicos: por um 
Linha D'Água (Online), São Paulo, v. 31 , n. 1, p. 193-220, jan.-abril 2018

Resumo acadêmico. In: SILVA, E. M. (Org.). Professora, como é que se faz? Campina Grande: Bagagem, 2012b, p. 43-64.

Recebido: 19/10/2017.

Aprovado: 11/01/2018. 
Linha D'Água (Online), São Paulo, v. 31 , n. 1, p. 193-220, jan.-abril 2018 